\title{
The calorific value measurement of methane using metal burner
}

\author{
Joohyun Lee ${ }^{1, a}$, Suyong Kwon ${ }^{1}$ and Wukchul Joung ${ }^{1}$ \\ ${ }^{1}$ KRISS, 267 Gageong-Ro, Yuseong-Gu, Daejeon, Republic of Korea
}

\begin{abstract}
With the diversification of the natural gas origin and the variations of the gas composition, the accurate determination of the gas calorific value is very important in the natural gas industry and the national standardization. A new reference gas calorimeter is developed by KRISS in Korea based on the isoperibolic principle. In this principle, a gas burner is placed in the calorimeter vessel filled with water and the calorimeter is placed in the constant temperature water bath. Methane, oxygen, argon gas are injected in the gas burner and the combustion takes place for 30 minutes. The temperature variation of the water in the calorimeter vessel is measured by Pt 25 thermometer. Electrical heater coils around the heater and simulates actual combustion process to find the heat capacity of the whole calorimeter vessel. The gas burner is usually made of pyrex glass but it has the disadvantages of the brittleness and irregular manufacturing. A metal burner is first invented and applied in this study to achieve precise manufacturing and standardization as well as the hardness. A calorific value of methane is measured with the developed gas calorimeter and the result shows within $0.4 \%$ difference between the experiment and the reference.
\end{abstract}

\section{INTRODUCTION}

Natural gas consumption constitute over $20 \%$ among whole energy sources and the demand will continue with the development of bio-gas and shale gas in the future. The composition of the natural gas depends on where and when the gas is produced. So the calorific value of each natural gas is different each other. Because natural gas is priced based on energy not volume, the accurate measurement of the gas calorific value is very important. Typically the calorific value of the natural gas is measured using gas chromatography specified in International Standard ISO 6976. However, the direct burning method of gas calorific value is considered to be more accurate than gas chromatography.

PTB developed an isoperibolic gas calorimeter to measure the superior calorific value of methane. The experiment showed $0.006 \%$ deviation from the ISO 6976 value with $0.05 \%$ uncertainty. LNE also constructed isoperibolic gas calorimeter and measured the calorific value of methane. The measurement result was $0.58 \%$ difference with the ISO 6976 value. The gas burners in these gas calorimeters are made of glass. The glass burners have low heat capacity and transparency. However, it is easily broken and very difficult to make as I designed. KRISS developed an isoperibolic gas calorimeter containing metal burner and the methane calorific value was measured. The metal burner can be manufactured close to the design and has hardness. Also, metal burner can be manufactured the same between burners. With these benefits, the standardization of the gas burner is expected to be possible with metal burner.

\section{EXPERIMENTAL APPARATUS AND EXPERMENTAL PROCEDURE}

The gas calorimeter is composed of three units; gas supply unit, constant temperature bath containing combustion unit (calorimeter vessel and gas burner) and combustion gas analyser as shown in Figure 1. The calorimeter vessel is made of stainless steel with the $2 \mathrm{~cm}$ insulating materials inside to minimize heat leakage. Gas burner is placed in the calorimeter vessel. The gas burner is made of stainless steel and it has window in order to observe the flame during the combustion as shown in Figure 2. In the calorimeter vessel, water temperature is homogenized by stirrer. Two thermistors(GE sensing AS115) and one PRT 25S(Fluke 5628) are installed to measure the water temperature. Thermocoax two-wire heating resistance is wound around the burner to determine the heat capacity of the calorimeter vessel. The bath temperature is set to $25^{\circ} \mathrm{C}$ for the whole experimental process. The same power as the methane calorific value is dissipated by the heating wire and temperature rise of the water in the calorimeter vessel is recorded to evaluate the heat capacity of the calorimeter vessel.

\footnotetext{
${ }^{\mathrm{a}}$ Corresponding author: joohyun.lee@kriss.re.kr
} 
For the complete combustion of methane, oxygen and argon gas are supplied to the gas burner. The methane is supplied by one nozzle at the center of the burner and another nozzle surrounds the center nozzle providing oxygen. Argon gas is injected for the stable of the flame. All the gas flow rates are controlled and measured by MFC. The methane gas is filled in the cylinder of $50 \mathrm{~mL}$ and the mass of the supplied gas is measured by measuring the cylinder weight before and after the combustion experiment. Combustion of methane is initiated by ignition using high voltage $(16.5 \mathrm{kV})$ transformer. The combustion of methane continues for approximately 30 minutes and almost $1 \mathrm{~g}$ of methane is burnt. The burnt gas flows into the $\mathrm{H}_{2} \mathrm{O}$ absorption tubes filled with molecular sieves to measure the weight of the formed water during the combustion process. In order to confirm the complete combustion, $\mathrm{CO}$ IR analyser (Thermo Scientific Model 48i) monitors the $\mathrm{CO}$ concentration of the burnt gas.

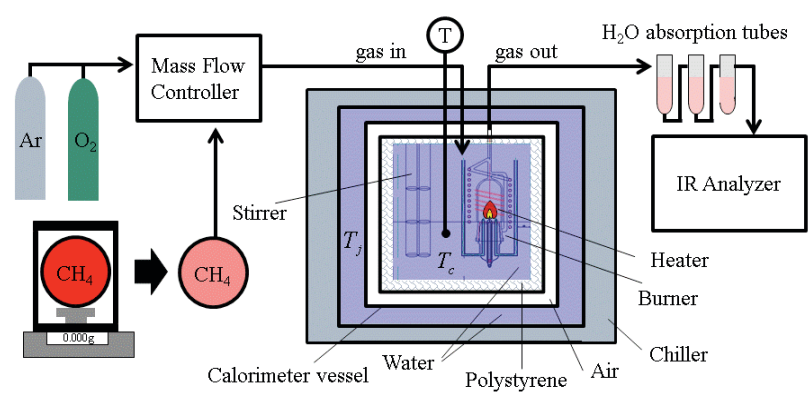

Figure 1. Experimental apparatus of gas calorimeter
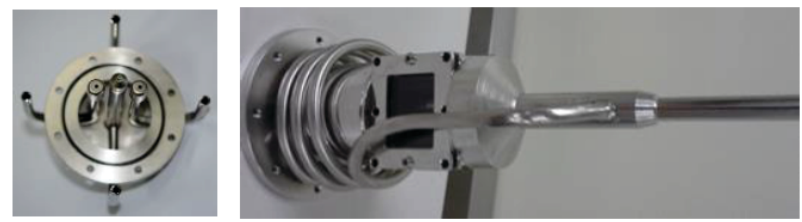

Figure 2. Upper part(Left) and lower part(Right) of the metal jacket burner

\section{RESULTS}

Electrical calibration was performed before the combustion experiment and the result is shown in Figure 3. The applied power to the heating resistance was $26.97 \mathrm{~W}$ which is almost same as calorific value of methane. The heat capacity $\left(\mathrm{C}_{\mathrm{cal}}\right)$ of the calorimeter vessel can be calculated by (1). In (1), $\mathrm{E}_{\mathrm{elec}}$ indicates the electrical energy liberated in the calorimeter vessel and $\Delta$ $\mathrm{T}_{\text {elec }}$ means the temperature rise during the electrical heating. The calculated heat capacity of the calorimeter vessel was $29.22 \mathrm{~kJ} /{ }^{\circ} \mathrm{C}$.

$$
C_{\text {cal }}=\frac{E_{\text {elec }}}{\Delta T_{\text {elec }}}
$$

After the electrical calibration, combustion experiment has been performed under the optimum gas flow condition. The optimum condition was sought by varying the flow rate of the oxygen and monitoring the $\mathrm{CO}$ concentration. Figure 4 shows the temperature profile of the methane combustion. The calorific value of the methane can be calculated by (2) in which, $\Delta T_{\text {comb }}$ indicates the temperature increase by the methane combustion and $\Delta \mathrm{m}_{\text {gas }}$ is the mass of the burnt methane. The measured calorific value of the methane was 55.29 $\mathrm{kJ} / \mathrm{g}$ which is $0.4 \%$ difference with the value specified in ISO 6976. The uncertainty of the experiment was evaluated as $1.1 \%$. The repeatability and the measurement of the heat capacity of the calorimeter vessel were the major factors influencing the uncertainty.

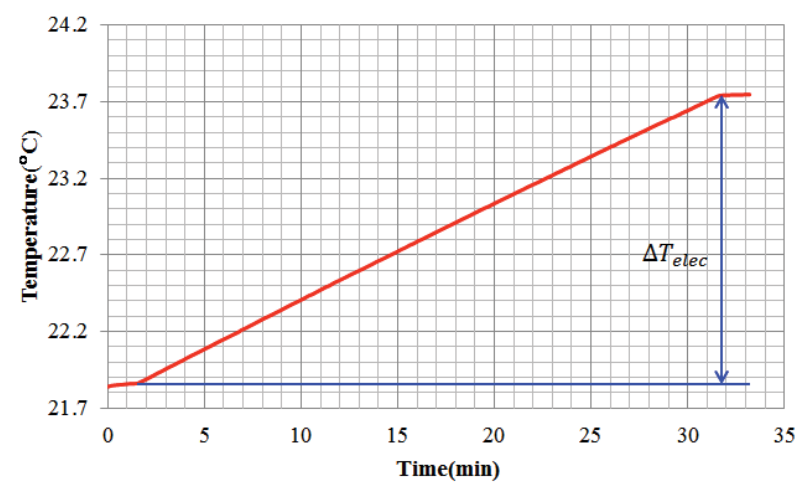

Figure 3. Temperature profile of the electrical calibration

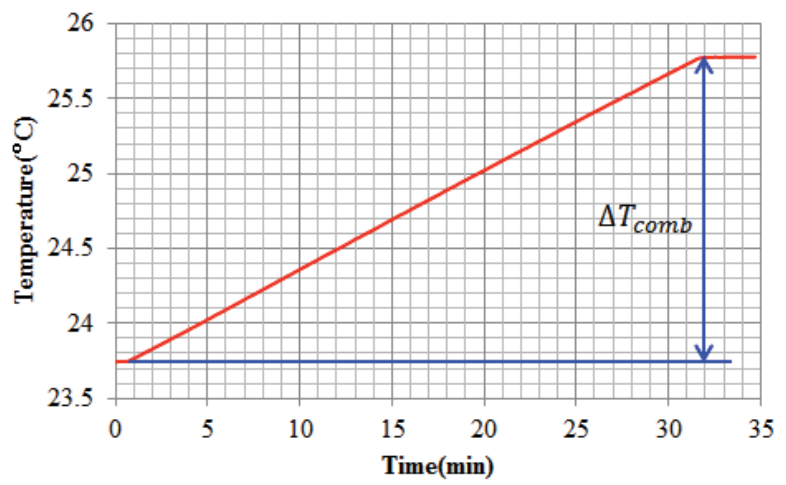

Figure 4. Temperature profile of the methane combustion

$$
H_{s}=\frac{C_{c a l} \Delta T_{c o m b}}{\Delta m_{g a s}}
$$

\section{CONCLUSION}

In this study, reference gas calorimeter was successfully developed using metal jacket burner for the first time. The calorific value of the methane was measured and the result showed the promise of the metal jacket burner. The developed calorimeter need to be improved for the better measurement. In order to achieve more accurate data, the amount of the unburnt gas should be measured more accurately and the exact amount of electric power need to be measured. For the future work, the smaller burner made of stainless steel needs to be developed for the 
portable gas calorimter as well as the improvement of the current calorimter.

\section{References}

1. P. Schley, M. Beck, M. Uhrig, S. M. Sarge, J. Rauch, F. Haloua, J.-R. Filtz, B Hay, M. Yakoubi, J. Escande, A. Benito, P.L. Cremonesi, Int. J. Thermophys, 31 (2010)

2. F. Haloua, B. Hay, J.-R. Filtz, J. Therm. Anal, 97 (2009) 